\title{
Max Engammare, L'ordre du temps. L'invention de la ponctualité au XVI siècle
}

\section{Dario Cecchetti}

\section{Q OpenEdition}

1 Journals

\section{Edizione digitale}

URL: http://journals.openedition.org/studifrancesi/30042

DOI: 10.4000/studifrancesi.30042

ISSN: 2421-5856

\section{Editore}

Rosenberg \& Sellier

\section{Edizione cartacea}

Data di pubblicazione: 1 avril 2006

Paginazione: 139-140

ISSN: 0039-2944

\section{Notizia bibliografica digitale}

Dario Cecchetti, «Max Engammare, L'ordre du temps. L'invention de la ponctualité au XVIe siècle», Studi Francesi [Online], 148 (XLX | I) | 2006, online dal 30 novembre 2015, consultato il 19 avril 2021. URL: http://journals.openedition.org/studifrancesi/30042; DOI: https://doi.org/10.4000/studifrancesi. 30042

Questo documento è stato generato automaticamente il 19 avril 2021.

\section{(c)}

Studi Francesi è distribuita con Licenza Creative Commons Attribuzione - Non commerciale - Non opere derivate 4.0 Internazionale. 


\title{
Max Engammare, L'ordre du temps. L'invention de la ponctualité au XVI siècle
}

\author{
Dario Cecchetti
}

\section{NOTIZIA}

MAX ENGAMMARE, L'ordre du temps. L'invention de la ponctualité au XVI' siècle, Genève, Droz («Cahiers d'Humanisme et Renaissance», $n^{\circ} 70$ ), 2004, pp. 263.

1 Max Engammare, riunendo, ampliando e dando forma di volume coerente e di vasto respiro a precedenti sue indagini, offre al cinquecentista un lavoro non solo ricco di dati, ma anche appassionante, in cui impiega le sue competenze di storico della spiritualità unite all'apporto di una illustre tradizione sociologica, da Max Weber a Norbert Elias a Michel Foucault (con le cui opere entra in dialogo), per affrontare un problema di grande rilevanza filosofica e illuminante per ricostruire la mentalità di un'epoca e di una cultura: quello del rapporto dell'individuo col 'tempo', in una prospettiva di contabilità esistenziale per quanto riguarda i momenti che scandiscono la giornata, se non la vita intera. Se una sintesi di grande impegno ed estensione, L'Ordre du temps (Paris, Bibliothèque des histoires, 1984) di Krzysztof Pomian, aveva già cercato di percorrere la cronometria, la cronografia e la cronologia, essenzialmente moderne e contemporanee, Engammare concentra e delimita rigorosamente la sua attenzione all'area cinquecentesca, in particolare a quella protestante e ginevrina. Non che «attraverso i secoli non ci siano stati esempi cattolici di uomini e di donne contabili del loro tempo al minuto preciso, ma - secondo l'A. - l'origine di questo rapporto minuzioso con il tempo sembra prendere nascita nel mondo protestante di origine calvinista». Forse quest'indagine sembra ideologizzare e confessionalizzare eccessivamente quella che l'A. definisce l'invention de la ponctualité. Invenzione, comunque, che trova punti d'appoggio innegabili nel protestantesimo cinquecentesco che costretto, se non altro per la soppressione del culto - e di conseguenza delle 
festività - dei santi, a riproporre scansioni e organizzazioni nuove del calendario, crea una nuova spiritualità, che in modo affascinante e con grande abbondanza di fonti Engammare etichetta come spiritualité du temps. Il punto di partenza dell'indagine è Calvino e la sua organizzazione personale del tempo (cap. I), ma il cammino del libro «è dal particolare al generale per ritornare al particolare, rivendicando una storia totale che faccia posto alla storia delle idee, alla storia della teologia, alla storia letteraria, alla storia del libro, alla storia della pedagogia e anche alla storia della filologia». Nello sforzo dei teologi e pastori ginevrini di scandire la giornata del fedele (ricomponendo un habitus devozionale nuovo) in maniera diversa dalla scansione delle Ore canoniche cattoliche, noi assistiamo alla creazione di una psicologia collettiva - per quanto concerne il reagente temporale - profondamente diversa da quella della Chiesa non riformata. In questa prospettiva di ricerca si situa il cap. II, consacrato a quel fatto centrale della liturgia e vita spirituale calvinista che è il sermone, qui studiato nei suoi risvolti di esigenze di 'orario'. Un capitolo studia i nuovi calendari stabiliti dai protestanti, a livello europeo (a Ginevra calvinisti, in Inghilterra anglicani, in Germania luterani): calendriers historiaux, che sostituiscono la memoria dei santi, dunque della tradizione cattolica, con la memoria dei grandi fatti e personaggi del protestantesimo. Altri due capitoli affrontano il mondo letterario francese del Rinascimento. Il primo studia due trattati dell'epoca, uno cattolico di Pontus de Tyard, l'altro protestante di Pierre Viret, e li raffronta con testi ronsardiani, evidenziando le differenze di percezione del dato temporale fra le due aree confessionali. Il secondo offre una carrellata di riflessioni letterarie sull'Ordre $d u$ jour: in successione, approcci di Guillaume Guéroult, Montaigne, Rabelais. Engammare conclude affermando che «in terra calvinista l'istaurazione della puntalità favorisce delle strutture sociali che possono essere analizzate, in ragione del controllo disciplinare fondato su un ordine del tempo». Libro appassionato, ove la ricostruzione erudita sfiora spesso l'autobiografismo spirituale, ma che offre una messe di dati e testimonianze interpretate sempre con grande intelligenza. 